\title{
Onychomadesis due to hand-foot-mouth disease
}

\section{Patricia Chang1, Edgar De León Juárez²}

\author{
${ }^{1}$ Department of Dermatology, Hospital General de Enfermedades IGSS and Hospital Ángeles, Guatemala, ${ }^{2}$ Student, Hospital \\ General de Enfermedades IGSS and Hospital Ángeles, Guatemala
}

Corresponding author: Dr. Patricia Chang, E-mail: pchang2622@gmail.com

Sir,

\section{Case I}

Male patient, 2 years of age, who is taken to the clinic for disseminated dermatosis to the peribucal region, lips, back of hands and palms, constituted by vesicles and blood crusts (Figs. la-d), and is diagnosed with mouthhand-feet disease 5 weeks after re-consultation due to onycopathy disseminated to both hands fingernails, and the right foot, manifested by a separation of the nail plate from the proximal fold (Figs. 2a and b). The rest of the physical examination was within normal limits and there is no significant family or personal background.

\section{Case II}

Female patient, 7 years old, coming to the clinic because of a four-week-old localized onycopathy in fingernails due to "fungi", presenting alterations in fingernails at index and ring fingers of the right hand and index of the left, manifested by separation of the nail plate from the proximal fold (Figs. $3 a-3 e)$. The rest of the physical examination was within normal limits.

The patient's mentions that prior to this picture the girl presented disease in mouth, hands, and feet soles, with vesicles. There is no significant family or personal background.

Diagnosis is made of onychomadesis secondary to mouth-hand-foot disease.

Onychomadesis is the proximal detachment of the nail plate [1]. It is the result of temporary matrix growth interruption [1-3]. It is associated with autoimmune, systemic diseases; trauma, use of medications, hereditary factors and infections [1-4] (Table 1).

Among the infectious causes, the one that is most frequently associated with onychomadesis is the mouthhand-foot disease $[1,3,5]$. It is an infection caused by viruses of the Enterovirus family [5,6]. It usually affects children under 10 years of age, although cases have been reported in adults [5]. In some regions, seasonal outbreaks are reported in spring and autumn [6]. This family of viruses consists of 10 species. The serotypes of human enteroviruses are divided into four species: A-D [7]. Coxsackie virus A16 and Enterovirus 71 are the two serotypes most frequently associated with the disease $[1,5,7]$. It characterizes by fever, malaise, odynophagia and vesicles that affect palms, plants, buttocks and oral mucosa [7], as well as oral ulceration of the mucous and gingival membranes, the soft palate and tongue $[1,5]$. Blisters usually appear on the back and side edges of the limbs, on an erythematous basis [1]. The initial picture resolves between 3 and 10 days, with an average of 6 days $[1,6]$. Subsequent to the initial picture, onychomadesis has been reported.

The first report of onychomadesis secondary to mouthto-foot disease was in 2000, in five children from Chicago, Illinois. In 2004, four cases were reported in Europe, and since 2008, isolated cases and outbreaks have been reported in different cities of Spain [7]. Cases have also been reported in France, Belgium, Italy, Finland, the United States, Japan and Taiwan, all in children under 7 years of age [1]. Onychomadesis occurs in a range between 4 and 10 weeks after the resolution of the initial symptoms [1,5-8]. And, although it has been proposed that infections by multiple enterovirus serotypes or specific serotypes $(\mathrm{A} 6, \mathrm{~A} 10, \mathrm{Bl})$ are responsible for this manifestation, no study has been 
Table 1: Causes of onychomadesis

\begin{tabular}{|c|c|}
\hline Type & Diseases \\
\hline Autoimmune & $\begin{array}{l}\text { Pemphigus vulgaris, alopecia areata, nail psoriasis, pustular psoriasis, pemphigoid gestationis, linear IgA disease, telogen effluvium, bullous } \\
\text { pemphigoid, Guillain-Barré syndrome, epidermolysis bullosa acquisita, among others. }\end{array}$ \\
\hline Systemic & $\begin{array}{l}\text { Stevens-Johnson syndrome, major depressive disorder, immunodeficiency, diabetes mellitus, severe sepsis, myocarditis, pancreatitis, } \\
\text { myocardial infarction, erythema nodosum, myelomatosis, Raynaud disease, erythroderma, contact dermatitis, epilepsy, hypopituitarism, } \\
\text { rheumatic fever, chronic kidney disease, Kawasaki disease, mycosis fungoides, peritoneal dialysis, zinc deficiency, gastrointestinal bleeding } \\
\text { postcardiac arrest, hyperparathyroidism, reflex sympathetic dystrophy, carpal tunnel syndrome, hemodialysis, severe dysmenorrhea, chronic } \\
\text { paronychia, and hypocalcemia. }\end{array}$ \\
\hline Trauma & Fractured olecranon or wrist, manicure, high-altitude expeditions, deep saturation dives, and road running. \\
\hline Medication & $\begin{array}{l}\text { Chemotherapeutic agents, antiepileptics, radiation therapy, some antibiotics, retinoids, lithium, octreotide, lead, corticosteroids, azathioprine, } \\
\text { itraconazole, and arsenic. }\end{array}$ \\
\hline Hereditary & Heimler syndrome, hyper-IgM syndrome, and idiopathic sporadic onychomadesis. \\
\hline Neonatal & Stresses in utero \\
\hline Infections & $\begin{array}{l}\text { Diphtheria, measles, mumps, varicella virus, syphilis, typhoid fever, scarlet fever, malaria, Candida spp, Trichophyton tonsurans, and } \\
\text { hand-foot-mouth disease. }\end{array}$ \\
\hline
\end{tabular}

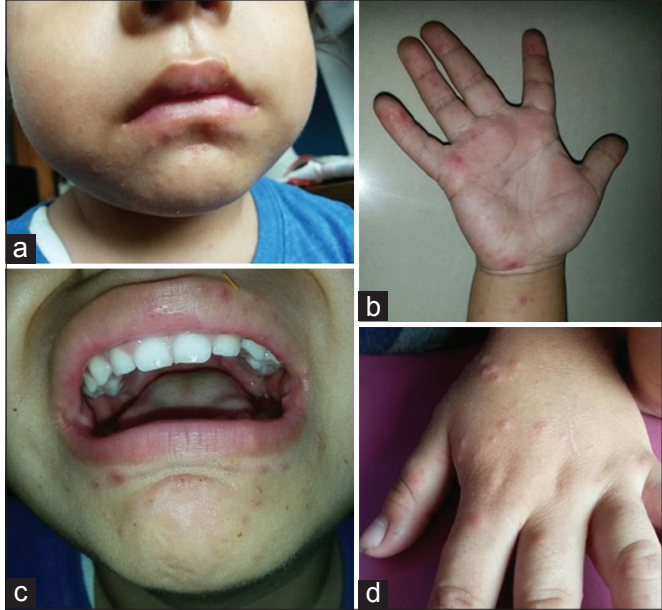

Figure 1: Hand-foot-mouth disease cutaneous lesions

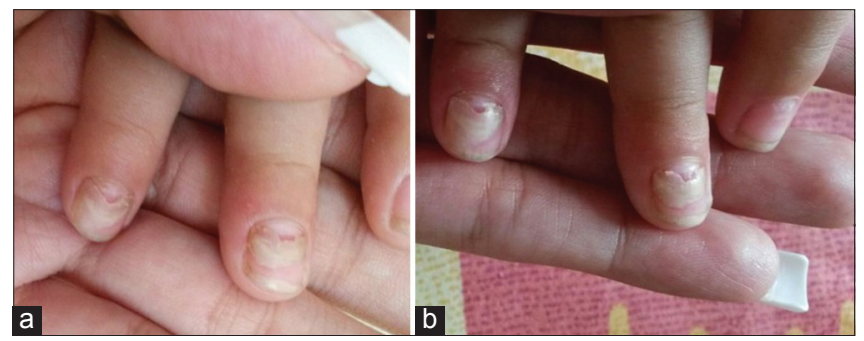

Figure 2: Separation of the nail plate from the proximal nail folds on fingernails 5 weeks after hand-foot-mouth disease

able to confirm this relationship with statistically significant evidence $[1,7]$. What has been shown is that serotype A6 has been reported more frequently in onychomadesis outbreaks secondary to this disease. The reason, it is believed, is that this serotype causes a more severe and widespread disease $[1,6]$.

The mechanism by which onychomadesis arises as a sequel to mouth-hands-feet disease is also not known with certainty, but several hypotheses have been raised. One of the most accepted theories is that of Bettoli

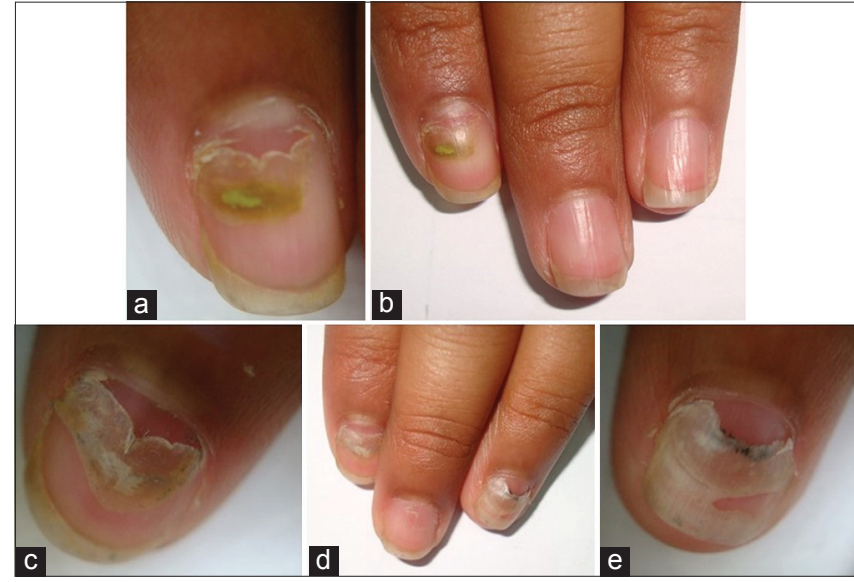

Figure 3a-e: Onychomadesis of fingernails 4 weeks after hand-footmouth disease

et al, which argues that matrix growth interruption is due to viral molecules or immune complexes deposits that cause embolism $[9,10]$. Cabrerizo and colleagues propose that it is secondary to direct damage by replication of the virus in the matrix $[5,10]$. This theory is based on two studies that identified the Coxsackievirus A6 in the scales of the lamina detached by PCR with reverse transcription $[5,6,10]$. It is also proposed that it is due to periungual inflammation or damage secondary to the appearance of vesicles near the nails (6). Other less popularized theories mention that it may be secondary to febrile illness, but this is discredited by some who note that not all patients report fever and that temperature rise is not high or persistent [6].

It being secondary to the use of drugs during the initial symptoms of the disease is not accepted either, has because no relationship has been reported between commonly used drugs, especially analgesics, and onychomadesis $[6,10]$. 


\section{CONSENT}

The examination of the patient was conducted according to the Declaration of Helsinki principles.

\section{REFERENCES}

1. Hardin J. Haber R. Onychomadesis: literature review. BJD. 2015;172:592-6.

2. Tosti A. Piraccini B. Biology of Nails and Nails Disorders. In: Goldsmith L. Katz S. Gilchrest B. Paller A. Leffell D. Wolff K. Fitzpatrick's Dermatology in General Medicine. $8^{\text {th }}$ edition. United States: Mc Graw Hill; 2008: Volume 1. 1009-1014.

3. Braswell M. Daniel R. Brodell R. Beau lines, onychomadesis, and retronychia: A unifying hypothesis. J Am Acad Dermatol. 2015;73:849-55.

4. Chang P. Escalante K. Onicomadesis. Twelve-case report. Dermatology CMQ. 2013;11:89-93.

5. Mortada I. Mortada R. Al Bazzal M. Onychomadesis in a 9-month-old boy with hand-foot-mouth disease. Int J Emerg Med.
2017;10:1-2.

6. Shin J. Cho B. Park H. A Clinical Study of Nail Changes Occurring Secondary to Hand-Foot-Mouth Disease: Onychomadesis and Beau's Lines. Ann Dermatol. 2013;26:280-3.

7. Bracho M. González-Candelas F. Valero A. Córdoba J. Salazar A. Enterovirus Co-infections and Onychomadesis after Hand, Foot, and Mouth Disease, Spain, 2008. Emerg Infect Dis. 2011;17:2223-31.

8. Gan X. Zhang T. Onychomadesis after hand-foot-and-mouth disease. CMAJ. 2017;189:E279.

9. Bettoli V. Zauli S. Toni G. Virgili A. Onychomadesis following hand, foot, and mouth disease: a case report from Italy and review of the literature. Int J Dermatol. 2013;52:728-30.

10. Jeelani S. Lanker A. Jeelani N. Onychomadesis Following the Outbreak of Hand Foot Mouth Disease in Children: A Study from North India. IJTDH. 2017;27:1-6.

Copyright by Patricia Chang, et al. This is an open access article distributed under the terms of the Creative Commons Attribution License, which permits unrestricted use, distribution, and reproduction in any medium, provided the original author and source are credited.

Source of Support: Nil, Conflict of Interest: None declared. 